\title{
A educação e o fracasso escolar: o eterno retorno do problema
}

Frederico Antônio de Araújo

Licenciado em Letras pela Universidade Federal de Minas Gerais (UFMG) e em Pedagogia pelo Instituto de Educacão de Minas Gerais (CPIEMG); mestre em Educação pela Universidade do Estado do Rio de Janeiro (UERJ). Professor do curso de Pedagogia da Faculdade de Educação da Universidade do Estado de Minas Gerais (FaE/UEMG).

\section{Resumo}

presente artigo discute questões referentes às explicações para ○ fracasso escolar, faz uma rápida trajetória sobre alguns mecanismos institucionalizados para resolver, minimizar e até explicar essa questão. Fala da criação da recuperação pela lei $n^{\circ}$. 5.692 de 197 I e vai mais adiante quando discute o fracasso escolar, sendo justificado à luz dos problemas dos fracassados: o aluno, a família, a escola, a comunidade e os professores como responsáveis ou culpados pelo fracasso escolar. Questiona a ideia de culpar a vítima e aponta a estrutura dominante da sociedade capitalista como a grande responsável pelo fracasso escolar. Sob aportes teóricos críticos, o artigo discute os problemas do fracasso escolar no Brasil.

Palavras-chave: fracasso escolar; recuperação; produção do fracasso; improdutividade da escola; teoria do capital humano. 
O fracasso escolar é um dos problemas mais antigos e mais sérios da educação brasileira. É um problema complexo que, frequentemente, volta às discussões tanto por parte dos governantes, quanto por parte da sociedade em geral e, principalmente, por educadores engajados no sentido de solucionar esse problema agudo, quase estrutural, da educação de nosso país.

O Brasil passou muitas décadas apresentando índices estatísticos alarmantes relativos ao número de crianças que fracassavam na escola. As estatísticas apontavam para índices maiores que $60 \%$ das crianças que não ultrapassavam a primeira série do ensino fundamental.

Aos poucos, sobretudo no final da década de 1990, foram surgindo mecanismos bastante poderosos para garantir a universalização do ensino, bem como a permanência da criança na escola. Mecanismos muito atuais, tais como a escola por ciclos, a aprovação automática e o fim das avaliações escolares e das provas escolares são alguns dos vários exemplos que poderíamos discorrer para confirmarmos nossas hipóteses.

Entretanto, muito antes do atual momento que estamos vivendo na educação do Brasil, na Lei Diretrizes e Bases da Educação, lei n 5.692 de 197I, já eram apresentados fortes mecanismos no sentido de garantir a universalização I34 do ensino sobretudo do ensino de primeiro grau', estendido por força de lei para oito séries (da primeira à oitava série), garantindo a gratuidade do ensino público dos sete aos 14 anos de idade. ${ }^{2}$

Um "dispositivo" extremamente interessante para garantir a tão propalada universalização do ensino, citada anteriormente, foi a criação da recuperação.

O artigo I4 da lei 5.692 de 197| rezava sobre a verificação do rendimento escolar, compreendendo a avaliação do aproveitamento e a apuração da assiduidade. A verificação do aproveitamento deveria ser expressa em notas ou menções. O parágrafo segundo desse artigo I4 dizia: “o aluno de aproveitamento insuficiente poderá obter aprovação mediante estudos de recuperação proporcionados obrigatoriamente pelo estabelecimento" (MINAS GERAIS, I97I).

O parágrafo terceiro da referida lei reza sobre a aprovação quanto à assiduidade. Ter-se-á como aprovado:

a) o aluno de freqüência igual ou superior a $75 \%$ [...]; b) o aluno de freqüência inferior a $75 \%$ que tenha tido aproveitamento

\footnotetext{
' As nomenclaturas ensino de primeiro e segundo graus foram substituídas por ensino fundamental e médio, mas por força do hábito, a nomenclatura da lei 5.692 de 1971 permanece entre os especialistas e estudiosos da área.

${ }^{2}$ Mudanças recentes transformaram o ensino fundamental de oito para nove anos, da primeira à nona série, crianças aos seis anos já podem entrar para a escola.
} 
superior a $80 \%$ da escala de notas ou menções [...]; e c) o aluno que não se encontre na hipótese da alínea anterior, mas com freqüência igual ou superior ao mínimo estabelecido em cada sistema de ensino pelo respectivo Conselho de Educação, e que demonstre melhoria de aproveitamento após estudos a título de recuperação (MINAS GERAIS, I97I).

A recuperação foi uma tentativa de racionalizar a eficácia do sistema público de educação escolar para evitar maiores congestionamentos do fluxo escolar e consequentemente reduzir os custos com o ensino e os gastos sociais com a educação. Nas décadas de 1970 e 1980 a recuperação final obrigatória passou a ser para a escola pública um mecanismo de aprovação massificada e para a escola particular uma fonte de renda a mais para os meses de dezembro e, em alguns casos, de janeiro também.

Supostamente, o papel da recuperação seria, segundo os discursos oficiais, um excelente mecanismo pedagógico para ampliar o tempo de aprendizagem dos alunos, garantindo melhor qualificação e aproveitamento escolar, mas o real papel da recuperação era outro, os seus objetivos implícitos eram da ordem de garantir a "produtividade da escola improdutiva". ${ }^{3}$

As sociedades democráticas afirmam a igualdade de todos perante a lei e a lei assegura para todos, independente e indiscriminadamente, o direito aos oito anos de escolarização pública e gratuita.

A reprovação e o fracasso escolar são onerosos para o sistema e para a sociedade, combatê-los se torna absolutamente essencial para garantir o, então, projeto desenvolvimentista do Brasil, o "milagre brasileiro". Para que se garanta a estratégia de uma escola produtiva, deve-se eliminar a reprovação e ampliar as taxas de retorno financeiro e investimento em educação.

A escola passa a ser vista e tratada como subsistema do sistema econômico e a educação passa a ser entendida como "capital humano". ${ }^{4}$

Nesse sentido, a recuperação vem delinear uma proposta de extensão do tempo para aprender, garantindo a igualdade de oportunidades e a assistência

\footnotetext{
${ }^{3}$ Utilizamos aqui o nome do livro de Frigotto (1999), "A produtividade da escola improdutiva: um (re) exame das relações entre educação e estrutura econômico-social e capitalista", como uma bela metáfora para explicar o que queremos dizer. ${ }^{4}$ A teoria do "capital humano" foi criada por pensadores e economistas da Escola de Chicago nas décadas de 1960 e 1970 , principalmente. Juntamente com Gary S. Becker e Milton Friedman, entre outros. Um dos seus expoentes Theodore W. Schultz, Nobel em Economia em 1979, escreveu, entre outros livros, um cujo nome é: "O capital humano: investindo em educação e em pesquisa", editado pela Zahar Editores em 1973. Escreveu também "Investindo no povo", publicado pela Editora Forense em 1987. A teoria do capital humano aponta para um fato interessante: sobre o impacto da escolarização relacionada às camadas mais pobres da população, tentando explicar esse impacto à luz de aplicações de modelos matemáticos e estatísticos. Entretanto, os críticos dessa teoria sempre indagaram: será que o aumento da escolaridade implicará o aumento da renda dos mais pobres e, com ela, distribuição de renda? Fica aqui a questão em suspenso e ainda sem resposta.
} 
individualizada aos alunos. Assim, esses introjetam, ideologicamente, o caráter paternalista da escola, incorporando o seu papel ideológico e assistencialista, ao mesmo tempo dissimulando, mantendo e, por que não dizer, aumentando as suas deficiências de aprendizagens.

A recuperação ao mesmo tempo compensa e reproduz as desigualdades sociais. Tratava-se de uma medida paliativa e compensatória que garantiria às camadas mais pobres da população uma sobrevida nos espaços escolares e a promoção dos alunos de uma série para outra, muitas vezes, com deficiências múltiplas de aprendizagem. A escola criava ali duas redes de ensino: a dos alunos bem sucedidos e a rede de ensino dos alunos sempre fadados à recuperação. Durante anos convivemos com essa mentalidade de ensino e de educação.

Um estudo bem delineado sobre a recuperação foi feito ainda na década de I 980 por Gonçalves ( $198 \mathrm{I}$ ). "A recuperação: dissimulando o fracasso da política educacional" foi uma dissertação de mestrado que contribuiu bastante para a produção deste trabalho, pois ajudou-nos a pontuar novas e atuais questões.

Os problemas do fracasso escolar começaram a intensificar-se, embora uma nova Constituição da República Federativa do Brasil tenha sido promulgada em 1988 e a nova lei, Diretrizes e Bases da Educação, tenha sido promulgada em 1996.

A Constituição da República Federativa do Brasil, em seu artigo 205, Seção I, Capítulo III (Da Educação, da Cultura e do Desporto) diz que: "A educação, direito de todos e dever do Estado e da família, será promovida e incentivada com a colaboração da sociedade, visando ao pleno desenvolvimento da pessoa, seu preparo para o exercício da cidadania e sua qualificação para o trabaIho" (BRASIL, 1988).

As palavras da Constituição Federal; os discursos de educação como pleno desenvolvimento da pessoa, preparando-a para a cidadania e para o trabalho; os discursos sobre qualidade da pessoa humana, direitos, liberdade, igualdade de condições, gratuidade de ensino fundamental; enfim, todas as formas como o Estado e os governos falam sobre educação são diferentes da realidade. Os "discursos" diferem-se da forma como a educação, principalmente a pública, vem sendo tratada pelos gestores do nosso país. Na prática, a teoria e a lei são diferentes.

O Brasil conseguiu avançar bastante em questões referentes à escolarização, mas "investir em qualidade" passa a ser a mais urgente prioridade. Nos últimos anos o que se fez para a educação em termos de qualidade foi muito pouco, garantiu-se a quantidade de alunos matriculados nas escolas tanto da rede 
pública quanto da rede particular de ensino, mas poucas foram as transformações no que se refere à qualidade do ensino e da educação propriamente ditos.

O ensino fundamental no Brasil apresenta hoje bons índices de matrículas e está quase que totalmente universalizado. A ampliação e a universalização do ensino juntamente com a racionalização foram algumas das medidas para "solucionar" os problemas da educação brasileira.

É importante chamar a atenção para um fato: nos últimos anos a educação e o ensino brasileiro, sobretudo a educação e o ensino públicos, têm sido relegados a um plano de total descaso das autoridades competentes e dos gestores da educação pública. Existe uma falta de compromisso quase que total com a rede pública de ensino. Os professores das escolas públicas de todo o país têm sido os grandes heróis dos últimos anos, apesar do descaso governamental e da depauperização a que foram expostos.

As discussões sobre o fracasso escolar devem envolver uma dimensão crítica mais ampla, perpassando por dimensões de caráter técnico e de formação do educador, entretanto ultrapassando os limites dessa discussão para uma discussão mais aprofundada de velhos e novos paradigmas da educação.

O fracasso escolar sempre existiu. Desde os primórdios da educação. Porém, ao se falar em fracasso, tem-se que perguntar: fracasso da escola ou fracasso do aluno? Qual é a escola que fracassa? Qual é o aluno que fracassa? Quais têm sido os instrumentos definidores e medidores do fracasso escolar? De quem é a culpa do fracasso escolar?

Se nem todos conseguem usufruir a contento de um direito, as causas e os culpados devem ser encontrados. Essas causas podem estar nos sujeitos que fracassam individualmente ou no grupo de sujeitos que fracassam, bem como, podem ser encontradas nas instituições que fracassam. Ora o aluno, ora a família, ora a escola, ora a comunidade, sempre houve a tentativa de encontrar um responsável pelo fracasso escolar.

Em diferentes períodos da história da educação no Brasil, sempre se tentou construir um responsável pelo fracasso escolar. $\mathrm{Na}$ escola tradicional, por exemplo, fracassado era o aluno que não detinha os conhecimentos considerados pelos professores como cultura. Na escola nova, por um outro ângulo, o fracassado da escola era o aluno que não se adaptava afetivamente ao espaço escolar, que apresentava dificuldades de socialização. $\mathrm{Na}$ escola tecnicista, fracassado passa a ser o aluno que não detém as técnicas e as competências necessárias para o trabalho que lhe foi indicado. 
O trabalho de SAVIANI (I984) pode nos ajudar a compreender melhor e mais claramente esses diferentes enfoques e mecanismos para explicar a sua teoria da marginalidade, bem como, grosso modo, as explicações para o fracasso escolar.

Em um trabalho mais recente, entretanto, Mattos (2007) é muito mais elucidativo e explicativo para a questão do fracasso escolar. A autora faz uma incursão na pesquisa etnográfica sobre o fracasso escolar no Brasil nas últimas duas décadas, relacionando a questão da regularização do fluxo escolar e seus consequentes problemas socioeducacionais para os jovens do Brasil. As explicações para o fracasso escolar nas últimas décadas vão desde teorias do déficit cognitivo, da carência cultural e da "cultura da pobreza", da "culpa da vítima" e da reprodução (PATTO, 1984; RYAN, I97I ; BOURDIEU; PASSERON, I975, citados por MATTOS, 2007).

\section{Compreendendo o fracasso escolar: uma tentativa de aproximação do universo semântico-conceitual}

Segundo o Moderno Dicionário Enciclopédico Brasileiro, fracasso é um substantivo masculino, cujo significado pode ser: "Estrondo de coisa que se quebra ou cai; baque; ruína; desastre; malogro; mau êxito" (ÁBILA FILHO, 1986, p. 363). Esse substantivo tem a sua origem no verbo fracassar. Verbo esse de várias regências. Como verbo transitivo direto, fracassar pode ser entendido como: "despedaçar; quebrar; derribar com estrépito; arruinar" (ibid). Como verbo intransitivo pode significar: "Falhar; ser mal sucedido; malograrse; produzir ruído, fragor" (ibid).

Rios diz que fracassar é, como verbo transitivo: "I. Quebrar; despedaçar com estrépito; 2. Arruinar". Como verbo intransitivo pode significar: "3. Produzir ruídos, fragor; 4. Não ter feito o desejado; 5. Ser malsucedido 6. Malograr-se, falhar" (RIOS, 200 I, p. 286).

Quando se fala em fracasso escolar estamos contrapondo a ideia de que há, por outro lado, o sucesso escolar.

O significado de "escolar" também merece uma atenção mais de perto. Escolar pode ser visto como "da escola", mas pode ser visto também como "do aluno" e até mesmo como "da comunidade escolar". A ideia de fracasso escolar se contrapõe à de sucesso escolar e se aproxima da de "exclusão escolar".

Se imaginarmos, conforme falado anteriormente, que a escola coaduna com 
o sistema maior por ser um subsistema do sistema econômico, político, sociocultural, e sabendo que a sociedade é segregacionista e separatista com distinções de classes sociais e "categorias sociais", poderemos entender o significado do fracasso escolar e do sucesso escolar. Quem são os fracassados, quem são os bem sucedidos?

A responsabilidade pelo fracasso sempre cai ora no aluno individualmente, ora na família, na escola e nos professores. Quando a responsabilidade cai sobre o aluno, ela está relacionada à falta de mérito pessoal ou dom inato para os estudos, as múltiplas dificuldades apresentadas são explicadas pelo "déficit". Se o aluno não usufrui adequadamente do processo de escolarização, se o aluno fracassa, o problema deve estar em causas subjetivas, a saber: problemas de saúde, má alimentação, desempenho físico, baixo índice cognitivo, cultura inferior ou ainda, o aluno pouco se esforça, é inapto e incompetente.

O fracasso escolar pode ser explicado também pelos problemas da família que, por ser mal estruturada e desorganizada, acaba dificultando o processo de aprendizagem dos alunos. Mas muitas vezes também o fracasso escolar se explica como sendo o fracasso da comunidade onde reside o aluno e a família. A comunidade pobre, carente, sem infraestrutura básica. Os problemas de moradia às vezes servem para justificar o fracasso do aluno.

A escola e os professores também são alvos para explicar e encontrar o culpado pelo fracasso escolar. A escola e os professores são incompetentes, seus métodos ineficientes, suas didáticas ultrapassadas e os professores são mal formados, sempre necessitados de uma melhor formação e constante capacitação. Muitas vezes eles são taxados como descompromissados e desleixados com o trabalho e com os alunos.

Muito raramente, ouvimos explicações para o fracasso escolar vinculados à organização e estrutura da escola, ao poder econômico e à sociedade capitalista, apresentando em seu cerne uma distinção entre as classes sociais (dominantes e dominados; opressores e oprimidos).

O discurso das classes dominantes sobre a escola e da escola, bem como as suas explicações para o fracasso escolar são o de que: I) a sociedade e a escola são iguais para todos. Todos são iguais, esse é um dos eixos do discurso liberaldemocratizante: "Liberdade, Igualdade, Fraternidade"; 2) O acesso à escolarização é assegurado por força de lei, proporcionando a oportunidade educacional a todos indistintamente. $O$ que as classes dominantes não propagam jamais é o duplo papel da escola, dominar e reproduzir, legitimando o 
saber e a cultura dominantes e perpetuando a diferença entre as classes sociais. (BAUDELOT; ESTABLET, I977; BOURDIEU; PASSERON, I992; FREIRE, 1979; FOUCAULT, 2007; SNYDERS, 198I).

Os alunos que fracassam estão fora dos padrões da escola e a culpa pelo fracasso é única e exclusivamente suas, a culpa pelo fracasso é subjetiva e devese aos sujeitos que fracassam individualmente.

Evidentemente os discursos contrários e críticos à escola e à sociedade capitalistas não coadunam com aqueles que, em alguma medida, beneficiamse do poder, da opressão e da pedagogia bancária, conforme apontou-nos o excepcional Freire (1979).

Perceber a organização da sociedade e da escola capitalistas como responsável pelo fracasso escolar, bem como a estrutura política e econômica como a responsável por esse fracasso, é difícil e, muitas vezes, impossível de ser percebido. É mais fácil culpar a vítima.

Como e para que responsabilizar e culpar a organização da sociedade capitalista se nós podemos culpar e responsabilizar o aluno, a família, a comunidade e o professor? Entretanto, a escola está a serviço das classes, da cultura, do fazer e do pensar dominantes, isso é inegável.

140 O aluno pobre fracassa, a criança pobre fracassa, a comunidade carente fracassa, a escola pobre e pública fracassa, a família pobre fracassa, os pobres professores sem estímulo, sem salário digno, sem planos de carreira fracassam e todos são os responsáveis pelo fracasso escolar. Mas a realidade é dinâmica, permeada de crises e contradições que geram novas sínteses, novas mudanças, impulsionando a história.

Refletir sobre a educação no Brasil e sobre o fracasso escolar ainda se faz absolutamente necessário. Não podemos deixar-nos levar por discursos comodistas que querem imediatamente encontrar responsáveis ou culpados para o fracasso escolar. Há interesses dominantes nessas tentativas espúrias - o interesse de culpar a vítima - e, dentro disso, os interesses das classes sociais favorecidas com e no sistema ficam impunemente disfarçados. 


\section{Bibliografia}

ÁBILA FILHO, J. Moderno dicionário enciclopédico brasileiro. 16. ed. Curitiba: Educacional, 1986.

BAUDELOT, C.; ESTABLET, R. La escuela capitalista. México: Siglo Vientiuno, 1977.

BOURDIEU, P.; PASSERON, J. C. A reprodução: elementos para uma teoria do sistema de ensino. 3. ed. Rio de Janeiro: Francisco Alves, 1975.

MINAS GERAIS. Secretaria do Estado de Educação e Cultura do Estado de Minas Gerais. Lei n. 5.692, de 1971.

BRASIL. Constituição da República Federativa do Brasil. São Paulo: Atlas, 1988.

BRASIL. Lei de Diretrizes e Bases da Educação Nacional. Lei n. 9.394, de 1996. Brasília: s/ed. 1996.

FOUCAULT, M. Vigiar e punir: nascimento da prisão. 34. ed. Petrópolis: Vozes, 2007.

FREIRE, P. Pedagogia do oprimido. 7. ed. Rio de Janeiro: Paz e Terra, 1979.

FREITAS, L. C. Crítica da organização do trabalho pedagógico e da didática. Campinas: Papirus, 1995.

FRIGOTTO, G. A produtividade da escola improdutiva: um (re) exame das relações entre educação e estrutura econômico-social e capitalista. São Paulo: Cortez, 1999.

GONÇALVES, F. S. A recuperação: dissimulando o fracasso da política educacional. Dissertação (Mestrado em Educação) Faculdade de Educação da Universidade Federal de Minas Gerais, Belo Horizonte, 1981. 
MATTOS, C. L. G. A pesquisa etnográfica sobre o fracasso escolar no Brasil nas últimas duas décadas. Rio de Janeiro: Núcleo de Etnografia em Educação da Universidade do Estado do Rio de Janeiro, 2007. Mimeografado.

PATTO, M. H. S. A produção do fracasso escolar: histórias de submissão e rebeldia. São Paulo: T. A. Queiroz, 1984.

RIOS, D. R. Mini dicionário escolar da língua portuguesa. São Paulo: DCL, 2001 .

RYAN, W. Blaming the victim. New York: Vintage, I97I. Tradução de Carmen Lúcia Guimarães de Mattos, Fernanda Ramalho e Lúcia Mourão.

SAVIANI, D. Escola e democracia. 2. ed. São Paulo: Cortez, 1984.

SCHULTZ, T. W. Investindo no povo: o segredo econômico da qualidade da população. Rio de Janeiro: Forense, 1987.

. O capital humano: investindo em educação e em pesquisa. Rio de Janeiro: Zahar, 1973.

SNYDERS, G. Escola, classe e luta de classes. 2. ed. Lisboa: Moraes, I98I. 


\title{
The education and the failure pertaining to school: the perpetual return of the problem
}

\begin{abstract}
The present article argues referrinf questions to the explanations for the failure pertaining to school, makes a fast trajetory on some institutionalized mechanisms to decide, to minimize and until explaining the failure. It speaks of the creation of the recovery for law 5692/7 I and goes more ahead when the failure argues pertaining to school being justified to the light of the problems of the failed ones the pupil, the family, the school, the community and the professors as responsible or guilty for the failure pertaining to school. It is questioned idea to blame the victim and points the dominant structure of the capitalist society as great the responsible one for the failure pertaining to school. Under you arrive in port theoretical critics argue the problçems of the failuire pertaining to school in Brazil.
\end{abstract}

Keywords: failure pettaining to school; recivery; production of failure; unproductively of the school; theory of the human capital. 